\title{
Supporting the contribution of higher education to regional development: lessons from an OECD review of 14 regions throughout 12 countries $^{1}$
}

\author{
Francisco Marmolejo ${ }^{2}$ \\ Jaana Puukka ${ }^{3}$
}

\begin{abstract}
Higher education institutions (HEIs) can and do make a significant contribution to regional economic, social and cultural development. In a globalised economy, the relevance of the various activities conducted in those institutions is growing in importance and is subject to increasing scrutiny. However, failures of communication between regional stakeholders and HEIs reduce the effectiveness of their teaching, research and public service efforts and limit the understanding at the local level of their impact. These communication failures are often associated with due to weak or unclear policy signals, and conflicting agendas. In order to respond to this dilemma, the OECD implemented a research project that involved 14 regions across 12 countries. This paper aims at drawing some important lessons from the OECD study entitled "Supporting the Contribution of Higher Education Institutions to Regional Development".
\end{abstract}

Keywords: higher education; regional development; OECD.

\footnotetext{
1 A version of this paper was presented at the UNESCO Forum on Higher Education, Research and Knowledge Colloquium on Research and Higher Education Policy "Universities as Centers of Research and Knowledge Creation: An Endangered Species?” in Paris, France November $29^{\text {th }}-$ December $1^{\text {st }} 2006$.

2 Executive Director, Consortium for North American Higher Education Collaboration (CONAHEC), University of Arizona, USA. E-mail: fmarmole@email.arizona.edu.

3 Analyst, Organisation for Co-operation and Economic Development (OECD), IMHE Programme, Paris, France. E-mail: Jaana.puukka@oecd.org.
} 


\title{
Apoiando a Contribuição da Educação Superior para o Desenvolvimento Regional: Lições de uma Revisão da OCDE de 14 Regiões através de 12 Países
}

\begin{abstract}
Resumo: Instituições de ensino superior (IES) podem e fazem uma contribuição significativa para o desenvolvimento econômico regional, social e cultural. Numa economia globalizada, a relevância de várias atividades conduzidas naquelas instituições é crescente em importância e está sujeita a um aumento de uma avaliação minuciosa e cuidadosa. Entretanto, falhas de comunicação entre os agentes regionais e as IES reduzem a efetividade dos seus esforços no ensino, na pesquisa e no serviço público e limitam a compreensão do nível local de seus impactos. Estas falhas de comunicação estão frequentemente associadas aos sinais políticos fracos ou confusos, e agendas conflitantes. Com o propósito de responder este dilema, a OCDE implementou um projeto de pesquisa que envolveu 14 regiões através de 12 países. Este artigo objetiva retirar algumas importantes lições da pesquisa da OCDE entitulada "Apoiando a Contribuição das Instituições de Ensino Superior para o Desenvolvimento Regional".
\end{abstract}

Palavras-chave: educação superior; desenvolvimento regional; OCDE.

JEL: R 10.

\section{Introduction}

Following decades of expansion in higher education, policy attention in OECD countries has begun to focus on the outcomes of higher education including how universities and other higher education institutions contribute to regional development. With the processes of globalisation and localisation, the local availability of knowledge and skills and the transfer of technology and innovation to SMEs are becoming more and more important. In recent years there have been many initiatives across OECD countries to mobilize higher education in support of regional economic, social and cultural development.

What is higher education's regional engagement all about? What are its drivers and barriers? What does it mean to the governance and management of higher education institutions (HEIs) and how does it fit with the pursuit of world class academic excellence?

Higher education institutions can and do make a significant contribution to regional economic, social and cultural development. In a globalised economy, the relevance of the various activities conducted in those institutions 
is growing in importance and is subject to increasing scrutiny. Too often, however, failures of communication between regional stakeholders and higher education institutions reduce the effectiveness of their teaching, research and public service efforts and limit the understanding at the local level of their impact. These communication failures are often associated with due to weak or unclear policy signals, and conflicting agendas.

In order to respond to this dilemma, the Organisation for Economic Cooperation and Development (OECD) has been conducting, during 2005 and 2006, a comparative review of how these issues are addressed in 14 regions across 12 countries, with the objective of reinforcing the partnerships between institutions and regions.

This paper attempts to draw preliminary lessons from the OECD study entitled "Supporting the Contribution of Higher Education Institutions to Regional Development". This thematic review project managed by OECD's Institutional Management Higher Education Programme (IMHE) involved the participation of higher education stakeholders, policymakers, businesses, and community based organisations in each of the fourteen regions studied.

Preliminary findings suggest that if countries want to be globally competitive, regional innovation systems need to be strengthened. In order to achieve this, cooperation between higher education institutions, public authorities and the business sector becomes vital. Currently, many regions are characterized by an abundance of activity involving higher education in regional development in some way, but there is limited evidence of coherent action. It is also evident that there are often no proper incentives, indicators nor monitoring of the outcomes of this type of activity. Finally, a cultural change within HEIs is necessary since regional engagement, academic excellence, and research are often not seen as complementary activities.

\section{THE OECD/IMHE PROJECT}

Historically it has been taken for granted that higher education institutions (HEIs) foster regional development by preparing students, doing research, and conducting a variety of public service tasks. However, HEIs do not always systematically assess their roles in the development of their surrounding regions. This prevents them from further evaluating the effectiveness of their activities, improving their performance and demonstrating the importance of their work to themselves and to local stakeholders.

Nevertheless, throughout the world, HEIs and the cities and regions in which they are located are discovering the mutual benefits of working together. HEIs can help regions tap into a global source of knowledge and other resources through their multiple international linkages. Regions, in turn, can provide 
HEIs with resources to support the fulfilment of their missions as they relate to teaching, research and community service. To map progress on this work, the OECD Programme on Institutional Management in Higher Education (IMHE) in collaboration with the OECD Territorial Development and Public Governance Committee has conducted a comparative thematic review of 14 regions across 12 countries on how issues surrounding the regional engagement of HEIs are addressed in OECD countries.

Following the 1999 publication by the OECD of a report entitled The Response of Higher Education Institutions to Regional Needs, the IMHE project entitled Supporting the Contribution of Higher Education Institutions to Regional Development was launched in 2004 as a response to a wide range of initiatives across OECD countries to mobilise higher education in support of regional development. There was a perceived need to synthesize this experience into a coherent body of policy and practice. The work produced could then be used as a guide for institutional reforms and relevant policy measures including investment decisions seeking to enhance the connection of HEIs to regional communities. Current practice needed to be analysed and evaluated in a way that was sensitive to the varying national and regional contexts within which HEIs operate.

The methodology chosen for the project was a thematic review which was influenced not only by other OECD peer reviews, but also by the developmentally oriented evaluation projects commissioned by the Finnish Higher Education Evaluation Council ${ }^{4}$. There was no predetermined selection: instead twelve regions from ten OECD countries opted into the project which, in practice, started in early 2005. The regions were: Busan Metropolitan City (Korea), Canary Islands (Spain), Jutland-Funen (Denmark), the Jyväskylä region (Finland), the North East of England, Nuevo León (Mexico), the Øresund Region (Denmark/Sweden), the Sunshine-Fraser Cost Region (Australia), Trøndelag, the Mid-Norwegian region, Twente (the Netherlands), Valencia (Spain), and Värmland (Sweden). Later, by the end of 2005, two additional regions joined the project: Atlantic Canada and Northern Paraná in Brazil.

There were essentially two main criteria for accepting a region in the project: First, it needed to have a recognisable regional identity, (whether as a formally constituted administrative region or in some other way) with some history of working with HEIs; and second, all HEIs operating in the region were required to be engaged in the review in order to identify the impact of the entire higher education sector as well as the division of tasks and key partners.

These criteria and the selection process resulted in a wide variety of participating regions with different regional and national contexts and types of HEIs. The participating regions range from rural to metropolitan and from peripheral to central regions. The participating HEIs, on the other hand, 
include not only research intensive, but also vocationally and professionally oriented institutions. At the national level, the review embraces devolved as well as highly centralised governance systems.

\section{Context and issue}

Higher education institutions are seen historically as key actors in the production, preservation, and dissemination of knowledge. Since the foundation of the Bologna University, almost a millennium ago, the idea of a university as a place in which learned individuals transmit information and knowledge to learners has been evolving. In today's world it is understood that higher education institutions in societies all over the world are the main factor for the social and economic mobility of individuals, and in the long run, for societies. Moreover, in a context characterized by complexity and accelerated change, higher education faces important opportunities and challenges, many of which are new and unexpected.

The increased diversity of higher education institutions is reflected in the expansion of their roles and responsibilities. No longer is it merely expected that HEIs provide quality teaching and conduct sound and relevant research, but more and more they are expected to play a key role as agents of regional development. This engagement is to take place in an environment characterized by scarce and limited resources, increased scrutiny, and calls for transparency and accountability from a number of internal and external stakeholders.

This complex environment confronts institutional decision makers with recurrent dilemmas. A typical example is when institutions confront conflicting options in search for common ground between the institutional research agenda, the needs of surrounding industry, the priorities of external funding agencies, and the personal agendas of researchers (Ylijoki 2003). Decision makers face the need to ensure that their institutions become nationally and internationally competitive, while struggling to address the needs of the region in which they are located. In this context, institutions are compelled to orient themselves, and allocate internal resources, in such a way that often fields closer to market needs are favoured, while others such as the humanities and arts have difficulties surviving (Slaughter, S. and G. Rhoades, 2004). Similar challenges are faced by universities in dealing with the clamour of employers demanding the development of more flexible academic programmes. This pushes institutions to again favour fields and content closer to market needs. Finally, institutions confront pressures to be more active as agents for economic development, sometimes competing with entities created for that purpose by regional and national governments as well as by the business sector.

The focus of the OECD project described in this paper has been on collabo- 
rative working between HEIs and their regional partners. The intent was to establish a regional learning and capacity building process by assuring the active participation of all pertinent stakeholders. Higher education institutions, the regions with which they share a history of collaboration, public authorities responsible for national and regional territorial and higher education development, employers, NGOs and community-based organisations were all involved. The fundamental aim has been to enhance the partnerships between institutions and regions through a learning process initiate by this OECD project.

\section{Policies and programmes: a broader interpretation of development}

Regional development is often thought of in economic terms only. The OECD project briefing notes and recent research in the fields of regional development and higher education suggest a wider interpretation however. The OECD template guiding the self-evaluation process asked HEIs along with their regional partners in the context of national higher education and regional policies, to critically evaluate how effective they are in contributing to the development of their regions. Therefore, key aspects of the self evaluation relate to: the contribution of research to regional innovation; the role of teaching and learning in the development of human capital; the contribution to social, cultural and environmental development; and the role of HEIs in building regional capacity to perform in an increasingly competitive global economy.

The engagement of higher education institutions in regional development can have a number of dimensions, including: (1) knowledge creation through research and its exploitation via technology transfer; (2) knowledge transfer through human resources development, education, localising the learning process by work-based learning, graduate employment in the region, and continuing education and professional development; and (3) cultural and community development, creating the milieu of social cohesion and sustainable development on which innovation depends. HEIs can play a unique role in the region and its civil society by bringing together the various elements of national policy that deal with learning and skills, research and innovation, culture and social inclusion.

Based on the multiple dimensions of HEI regional engagement and the many roles they play, it is evident that the regional engagement agenda requires an institution-level response from a HEI with transversal coordination mechanisms. Figure 1, developed by Goddard and Chatterton (2003) describes this perspective. While the left hand side of the diagram refers to the three roles of HEIs, namely education, research and the third mission, the right hand side symbolises key dimensions of regional development such as innovation, 
skills and cultural and community cohesion. In order to serve the region in the best possible way, the HEI must bring together its three tasks within the community in a consistent and systematic way. At the same time, systematic mechanisms for bridging the boundary between HEIs and the region need to be put in place.

FIGURE 1 - A MULTIDIMENSIONAL REGIONAL ENGAGEMENT FOR HIGHER EDUCATION INSTITUTIONS
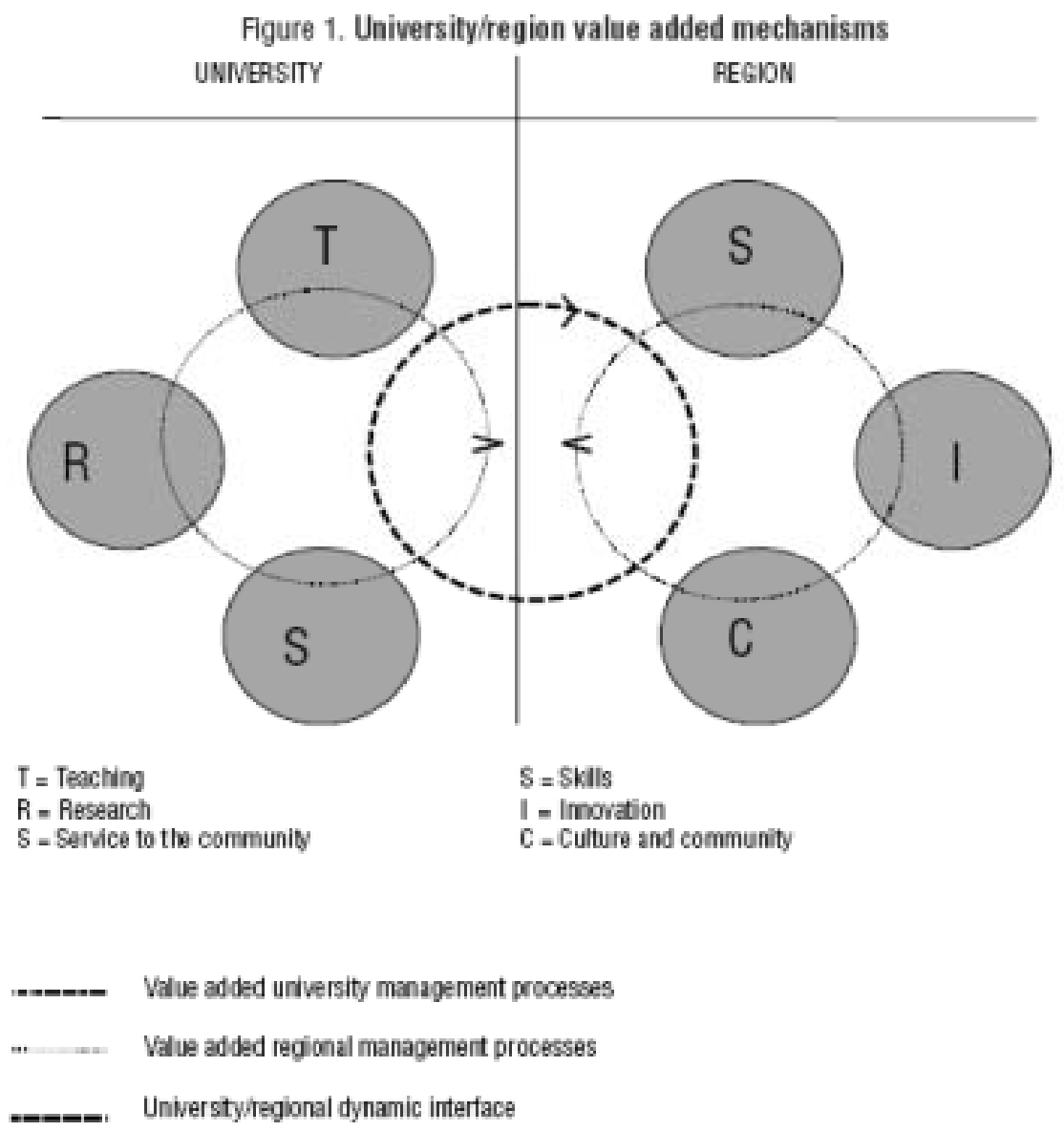

Source: Goddard \& Chatterton (2003).

While figure 1 represents an ideal scenario, in practice there are external and internal barriers preventing HEIs from becoming more regionally engaged. These include legal, cultural, structural, governance and financial barriers, among others. 
Although the legal mandate of higher education in many countries may contain a requirement for regional engagement or so-called "third role" activities, there are no major incentives or funding streams to support this requirement and most importantly, no set of indicators nor active monitoring of the outcomes. Regional development also remains a contested terrain within regional and national government. This leads to the involvement of many ministries or government agencies, often working in silos and sometimes sending mixed messages. As a result, many ministries of education remain region-blind. As far as it relates to higher education, regional development is also a contested terrain in the academic world.

In the global knowledge society, it is assumed that economic development strategies should focus on core regions, major cities and knowledge clusters. Leading higher education institutions in these regions are expected to generate and transfer new knowledge as global players. The emerging hierarchy of HEIs thus underpins the hierarchy of cities and regions. In these conditions, the key challenge is to establish regionally engaged HEIs with global standing. In this way polarisation in the knowledge economy can be countered and the pipelines of HEI innovation can be combined with the development of the region in which it is located. The mobilization of big science universities in support of regional development is still under way.

However, such a dual role leads to conflicting paths. First, there are perceived tensions between the pursuits of world class research and enhanced regional engagement. Some case studies suggest that there continues to be resistance within the research community against enhanced attention to regional engagement. The main argument is that a HEI does not have the capacity to engage in regional development but must give priority to research collaboration at the national and international levels. At the same time, incentive mechanisms and processes tend to over-value the importance of international engagement and participation of researchers in international academic networks, making involvement in regional development something of limited value or of secondary priority. Nevertheless, in many regions there is evidence that academic excellence and regional engagement can be complementary, mutually reinforcing activities where a world class university or its departments gain international profile through cooperating with regional stakeholders.

To institutionalise the third mission, there is a need to find a balance between allowing and encouraging individual initiatives and introducing a strengthened management core. If a HEI intends to play an active role in regional development, it must initiate a process of institutional adjustment and transform itself into an entrepreneurial university with a strengthened management core and professional management systems. 


\title{
4. Research results
}

\author{
4.1 Methodology
}

Recognizing that the relationship between an HEI and its region must be dynamic and employ a diversity of tools (Goddard 1999), and that institutions are under increased pressure to show the 'added value' of their varied functions in the region, the OECD project included the development of a methodology under which each region conducted a self-assessment. This self-assessment was later reconciled with the findings and recommendations of external peer review teams. Both, the regional self evaluation and the external review included an analysis of policies at national, regional and institutional levels, as well as extensive consultations with academic staff, institutional administrators, policy makers, officers from government agencies, business sector representatives and individuals representing non-governmental organisations.

The methodology of the project consisted of the following elements: (1) a common framework for regional self-evaluation developed by the OECD task group; (2) a Self-Evaluation Report by the regional consortium using OECD guidelines; (3) a site visit by an international Peer Review Team; (4) a Peer Review Report and a response from the region; and finally (5) analysis and synthesis by an OECD task group drawing upon regional case studies. There was also a commissioned literature review. All reports are published on the project website http://www.oecd.org/edu/higher/regionaldevelopment.

The OECD/IMHE intended to actively intervene in the participating regions. Therefore, as a way to enforce the partnership building process, the OECD guidelines requested that participating regions establish regional steering committees with the representation of key stakeholders in the public, private and third sectors. The steering committees were assigned the role of driving the process of self-evaluation and partnership building.

In practice, the regions were at different stages of maturity in capacity building. While for some regions the OECD project was the first opportunity to bring together the HEIs and other stakeholders to discuss the development of the region, some already had - to varying degrees - operational mechanisms in place for that purpose. For example, in the North East of England the existing higher education regional association (HERA), known as Universities for the North East or Unis4NE, took the responsibility for coordinating the exercise. In Busan, Korea, the Regional Innovation System (RIS) committee assumed the role of the Regional Steering committee. In Nuevo Leon, Mexico, INVITE, a newly created regional development state government agency coordinated the project, while in North Paraná, Brazil, a team of researchers from universities was commissioned to assume the role of the Regional Steering committee.

In each of the participating regions, the self-evaluation process was followed 
by a site visit by a Peer Review Team. Each team has had two international experts as well as a national expert and a team coordinator, usually from the OECD secretariat. Based on the review visit, the Self-Evaluation Report and other additional information, each Peer Review Team prepared a report analysing the situation and providing policy and practical advice to HEIs, and the regional and national governments. The final synthesis report drawing from the 14 reviews will follow in 2007.

In preparing their respective regional reports, each peer review team followed a suggested distribution of topics provided by the OECD, but had the freedom to write their report with no additional restrictions or directions. It was understood, however, that reports were merely a snapshot of an evolving process of development that included observations and suggestions intending to be formative and developmental rather than judgmental in any narrow sense.

Since the project included a wide array of institutions, regions, systems, policy environments, legal and regulatory frameworks, institutional and sociocultural backgrounds, etc. there are limitations in terms of comparability.

\subsection{Key preliminary findings}

The OECD project is at a stage in which all the reviews have been conducted. The initial workshop in which specific experiences were shared among participating institutions from the 14 regions that was conducted in Copenhagen during the second week of October of 2006 helped to discuss preliminary observations across regions. As mentioned earlier, the final general report is still being prepared for formal presentation to governments, higher education institutions, industry and other stakeholders at a meeting to be held in Valencia, Spain during the fall of 2007.

However, at this point in time, it is possible to outline some preliminary findings:

a) Building regional innovation systems: one need confirmed by the various reviews is that if countries want to be globally competitive, regional innovation systems must be built up in cooperation with higher education institutions, public authorities and the business sector. Usually, competitiveness policies and funding programmes are developed as top-down initiatives established by central governments with limited involvement of regional stakeholders in the decision making process. It is critical to involve the key regional a ctors as a necessary ingredient for success. There is ample evidence of a positive link between investment in regional innovation systems and economic competitiveness. In practice there are, however, internal and external barriers impeding HEIs from becoming more regionally engaged.

b) Proliferation of efforts but limited coordination: it is common to observe in participating regions that there has been an abundance of activity and a proliferation of projects in higher education institutions, business organisations, and 
government agencies. However, it is also common to observe that, in most of the cases, there is no coherent action, limited coordination and communication, frequent duplication of efforts and inefficiency in the use of limited resources.

c) Regional engagement is more than just economic development: in general, it is common to observe across regions involved in the project, the development and implementation of policies and incentives aimed at fostering the involvement of institutions in a variety of economic development activities (applied research, technology transfer, incubation of enterprises, etc.) coupled with a limited level of engagement and interest in equally important components such as social, environmental and cultural development.

d) Regional vs. international scope: there is also a perceived tension within HEIs between national and international excellence in teaching and research and regional engagement, despite the fact that numerous cases across OECD countries show that academic excellence and regional engagement can be complementary, mutually reinforcing activities.

e) Incentives: although higher education legislation in many OECD countries has a requirement for regional engagement or third role activities, there are often no proper incentives or funding streams to support this goal. At a more concrete level, higher education institutions and systems, in general, value traditional academic accomplishments in their recruiting, hiring, evaluating and promoting practices. Institutions are usually evaluated and ranked based on traditional criteria.

f) Measuring effectiveness: there is, in general, a lack of indicators and monitoring of outcomes. Recognizing that there are technical difficulties and political hurdles to be faced, it is critical to measure the outcomes of the regional development work of HEIs. Developing sound measures of the effectiveness of institutional engagement in regional development can provide extremely useful information and input for the improvement of higher education systems and individual institutions.

g) Changing the internal culture and management practices of institutions: there is a need for a cultural change within higher education institutions which gives more recognition to the importance to establishing a sound and effective management support infrastructure. This includes more adequate management of human resource policies and procedures, accounting and finance, information systems, and general support systems, among others.

h) Government innovation policies: competitiveness is no longer seen as something that needs to be imposed from the top-down, but instead as something to be driven by the regions themselves.

i) Context matters: comparative experiences and models from regions involved in the project are relevant and applicable to others insofar as they take into consideration the national, regional and institutional contextual framework in which they were originally developed.

j) HEIs as economic agents: HEIs are in many cases very important economic agents in the communities in which they are located. Sometimes they are the largest employer in the region. The scope, volume and multiplier effect of their activities isn't always properly and actively measured and monitored.

k) HEIs as "good citizens": a review of the collected reports permits the identification of some critical elements in establishing a dynamic and sustainable 
region, including: a globally competitive productive system; a persistent process of increasing social inclusion; a political commitment of regional communities to the protection and conservation of their natural environment; an increasing synchronization of intersectoral and territorial growth; and an enlarging collective perception of belonging to the region.

\section{A final note}

What do the preliminary outcomes of the OECD review tell us? How has the regional engagement agenda been assumed in different regions and at the level of individual institutions? In general, it all depends on the historical, social, political and legal framework in which higher education institutions and regional systems operate. However, although they may not seem comparable, the contrasting experiences observed in the various regions participating in the project provide extremely useful input and serve as a basis for further work at policy and operational levels.

Efforts like the one initiated by the OECD provide useful practically oriented research and collective reflection which deserve further attention and analysis. Some items for further consideration include:

a) Applicability: although general issues, trends, best practices and recommendations can be identified, it would be of limited practicality to produce specific or overly narrow prescriptions on what to do and what overall policies should be considered. Each of the participating regions, their institutions and their stakeholders have their own dynamics and contextual characteristics.

b) Dissemination and sharing of practices: there are benefits to merely being exposed to practices, approaches and lessons learned in different regions. Naturally, this means that the delivery of reports derived from this developmental rather than inspectorial project should be accompanied with a strong and well conceived dissemination and replication strategy. Otherwise the project's impact and overall effectiveness may be confined to actions in the participating regions and their institutions.

c) Building capacity: a sustained effort requires a set of actions aimed at building capacity not only at higher education institutions but also within the region. Otherwise, the institutionalization of these efforts may not be achieved.

d) Monitoring the process of review and improving it: the process of participating in the OECD project alone has led regions and their key stakeholders to engage in a process of reflection and analysis. This process should be reviewed and further improved in order to refine its effectiveness in the future. 


\section{References}

GODDARD, J.; CHATTERTON, P. (2003). "The Response of Universities to Regional Needs.” In: BOEKAMA, F. \& KUYPERS, E. \& RUTTEN, R. (Eds.). Economic Geography of Higher Education: Knowledge, Infrastructure and Learning Regions. London: Routledge.

OECD/IMHE. (1999). The Response of Higher Education Institutions to Regional Needs. Paris.

SLAUGHTER S. \& RHOADES, G. (2004). Academic Capitalism and the New Economy Markets, State, and Higher Education. Baltimore: The Johns Hopkins University Press.

YLIJOKI, O.-H. (2003). "Entangled in academic capitalism?: A case study on changing ideals and practices of university research." Higher Education, 45: 307-335.

Submissão: 27 de março 2008. Primeira resposta: 28 de abril de 2008. Aceite: 20 de fevereiro de 2009. 